\title{
Perbedaan Kemampuan Menyelesaikan Soal Cerita antara Siswa Bergaya Kognitif Reflektif dan Impulsif
}

\author{
Mu'jizatin Fadiana \\ Program Studi Pendidikan Matematika, Universitas PGRI Ronggolawe Tuban \\ Korespondensi:mujizatin000@gmail.com
}

\begin{abstract}
Abstrak. Penelitian ini bertujuan untuk membandingkan dua variabel yaitu kemampuan menyelesaikan soal cerita pokok babasan volume kubus-balok antara siswa yang bergaya kognitif Reflektif dan siswa yang bergaya kognitif Impulsif kelas $V$ sekolah dasar. Sampel pada penelitian ini adalab 19 siswa kelas V MI Nurul Huda Ketambul Palang Tuban. Instrumen yang digunakan adalab tes MFF (Matching Familiar Figures) dan tes kemampuan menyelesaikan soal cerita. Statistik wiji yang digunakan adalah Mann-Whitney. Hasil penelitian menunjukean ada perbedaan kemampuan menyelesaikan soal cerita antara siswa bergaya kognitif reflektif dan siswa bergaya kognitif impulsif kelas $V$ sekolah dasar.
\end{abstract}

Kata kunci: gaya kognitif impulsif, gaya kognitif reflektif, kemampuan menyelesaikan soal cerita

\begin{abstract}
This study aims to compare two variables namely the ability to solve the subject matter of the volume of cubes and rectangular prisms between students' with reflective and impulsive cognitive style in fifth grade elementary school. The sample was 19 fifth grade students of MI Nurul Huda Ketambul Palang Tuban. The instruments used were a test of MFF (Matching Familiar Figures) and a test for assessing the ability of solving problems. The results of this study were tested with the Mann-Whitney. Based on the test, it was obtained that the $U_{\text {test }}$ is the smallest tranking number. Thus, it can be concluded that there is a difference between the ability to solve problems on students' with reflective and impulsive cognitive style on fifth grade students in elementary school.
\end{abstract}

Keywords: cognitive impulsive style, cognitive reflective style, problem solving skill

\section{Pendahuluan}

Interaksi guru dan murid dalam pembelajaran matematika memiliki tingkatan kesulitan yang lebih tinggi dibandingkan pembelajaran yang lain karena objek kajian langsung matematika yang bersifat abstrak seperti halnya pada soal cerita. Oleh karena itu guru harus mampu menjelaskan pesan-pesan matematika abstrak tersebut agar lebih mudah diterima oleh siswa. Hudojo (2001) mengemukakan bahwa matematika berkenaan dengan ide-ide abstrak yang diberi simbol-simbol yang tersusun secara hirarkis dan penalarannya deduktif. Dengan demikian, jelas bahwa belajar matematika merupakan kegiatan mental yang tinggi. Karena struktur matematika bersifat hirarkis, belajar matematika yang terputus-putus akan mengganggu terjadinya proses belajar. Dalam proses belajar matematika, terjadi juga proses berpikir. Seseorang dikatakan berpikir bila 
orang tersebut melakukan kegiatan mental dan orang yang belajar matematika dapat dipastikan melakukan kegiatan mental. Solso (1995) mengemukakan bahwa berpikir adalah proses pembentukan representasi mental baru melalui transformasi informasi dengan interaksi kompleks atribut-atribut mental seperti: membuat keputusan, mengabstraksi, menalar, membayangkan, dan memecahkan masalah. Dalam berpikir, kita menyusun hubungan-hubungan antara bagian-bagian informasi yang telah kita terima didalam pikiran kita sebagai pengertian-pengertian. Galloti (dalam Warli, 2010) mengatakan bahwa berpikir didefinisikan sebagai sesuatu yang melampaui informasi yang diberikan. Kategori berpikir adalah pemecahan masalah, abstraksi, penalaran deduktif, dan pembuatan keputusan. Dalam berpikir orang akan menyusun hubungan antar bagian-bagian dan informasi direkam sebagai pengertian-pengertian. Dari pengertian tersebut terbentuk pendapat yang pada akhirnya ditarik suatu kesimpulan.

Keberhasilan pembelajaran matematika antara lain ditentukan oleh kemampuan gaya kognitif siswa sebagai penerima pesan pengetahuan matematika. Dalam pembelajaran guru harus menghadapi siswa-siswa yang memiliki perbedaan kemampuan pemecahan masalah, atau berfikir kreatif, serta memiliki perbedaan dalam cara memperoleh, menyimpan, serta menerapkan pengetahuan. Setiap siswa berbeda dalam cara pendekatan terhadap situasi belajar, cara menerima, mengorganisasikan dan menghubungkan pengalaman-pengalaman mereka, serta cara merespon metode.

Guru dan siswa memiliki cara-cara sendiri yang disukai dalam menyusun apa yang dilihat, diingat, dan yang dipikirkan. Perbedaan-perbedaan individu yang menetap dalam cara menyusun dan mengolah informasi serta pengalaman-pengalaman tersebut dikenal dengan "gaya kognitif ". Gaya kognitif merupakan variabel yang penting yang mempengaruhi pilihan guru dan siswa dalam bidang akademik, kelanjutan perkembangan akademik, bagaimana pembelajaran yang dilakukan, serta bagaimana siswa dan guru berinteraksi dalam kelas. Baik guru maupan siswa menunjukan cara-cara pendekatan yang berbeda dalam menerima atau memberikan pengajaran, sesuai gaya kognitif yang dimiliki. Soedjadi (2000) menjelaskan bahwa potensi perkembangan anak didik amat perlu dipahami oleh sorang guru dan orang tua, agar dapat dengan "tepat" memilih materi ajar maupun pengetahuan lain yang dipandang perlu.

Gaya kognitif mempunyai hubungan positif atau negatif dengan motivasi dan prestasi akademik, tergantung pada sifat belajarnya. Witkin (1977) menguraikan 4 karakteristik gaya kognitif. Pertama, lebih menaruh perhatian pada bentuk daripada isi aktivitas kognitif. Hal ini mengacu pada perbedaan idividu bagaimana merasa, memiliki, memecahkan masalah, belajar, dan berhubungan dengan orang lain. Kedua, gaya kognitif merupakan dimensi yang menembus. Ketiga, gaya kognitif bersifat tetap, tetapi bukan berarti tidak dapat berubah. Pada umumnya jika orang memiliki gaya kognitif tertentu pada suatu saat tertentumaka gaya kognitif tersebut pada hari, bulan, dan bahkan tahun berikutnya relatif tetap. Keempat, dengan mempertimbangkan nilai, gaya kognitif bersifat bipolar (dua kutub). Karakteristik ini penting untuk membedakan antara kemampuan intelektual dengan kemampuan yang lainnya.

Penelitian ini lebih memfokuskan pada gaya kognitif reflektif-implusifyang dikemukakan oleh Jerome Kagan tahun 1965. Kagan dan Kogan (1970) mengatakan bahwa dimensi reflektif-implusif menggambarkan kecenderungan anak yang tetap untuk menunjukan cepat atau lambat waktu menjawab terhadap situasi masalah dengan ketidakpastian jawaban yang tinggi. Dimensi reflektif-implusif adalah derajat/tingkat subjek dalam menggambarkan ketepatan dugaan pemecahan masalah yang mengandung ketidakpastian jawaban. Sedang Rozenwajg dan Corroyer (2005) menjelaskan gaya kognitif reflektif-impulsif didefinisikan sebagai sifat sistem kognitif yang 
mengkombinasikan waktu pengambilan keputusan dan kinerja (performance) mereka dalam situasi pemecahan masalah yang mengandung ketidakpastian (uncertainty) tingkat tinggi.

Kagan dan Kogan (1970) menjelaskan bahwa dimensi reflektif- impulsif juga mempengaruhi kualitas penalaran induktif. Anak-anak kelas $\mathrm{V}$ diberi tes tentang penalaran induktif. Prosedur pertama, anak diberi tiga atribut suatu objek dan mereka harus menebak objek tersebut. Prosedur kedua, anak ditunjukan tiga gambar urutan yang tepat, yang melukiskan pemulaan suatu urutan cerita. Kemudian anak diberi empat gambar lain dan diminta memilih sebuah gambar diantara empat gambar tersebut yang menggambarkan cerita berikutnya. Dari kedua prosedur tersebut anak-anak impulsif menjawab dengan cepat namun membuat banyak kesalahan dibandingkan dengan anakanak reflektif. Kenny (2007) menjelaskan perbandingan individu antara kelompok implusif dan reflektif menunjukan bahwa anak reflektif usia 7 tahun lebih komunikatif dibanding anak-anak impulsif pada umur yang sama. Selain itu, anak reflektif usia 7 tahun lebih sering mempertanyakan atribut yang diberikan kepadanya, dibanding anak implusif yang lebih mempertanyakan tentang kejadian spesifikasi dari atribut tersebut.

Untuk mengukur gaya kognitif impulsif-refleksif digunakan instrumen yang dikembangkan oleh kogan yang disebut maching familiar figures (MFF). Kogan dan Kagan (1970) mengatakan bahwa MFF adalah instrumen yang khas untuk menilai gaya kognitif implusif-reflektif. Kogan juga menjelaskan bahwa tes MFF pada anak telah ditunjukan satu gambar baku (standar) dan enam gambar yang serupa, hanya salah satu dari gambar tersebut sama dengan gambar yang baku. Tugas anak adalah memilih satu gambar yang sama dengan gambar yang baku. Variabel yang diamati adalah jumlah kesalahan dan ratarata waktu tanggapan pemilihan pertama. Jumlah semua item tes ada 10. Variabel yang diperhatikan dalam tes adalah waktu $(t)$ yang digunakan setiap kali menjawab dan frekuensi (f) menjawab sampai benar. Setiap kali anak menjawab akan dicatat waktu (dari pertama kali gambar ditunjukan) dan frekuensi menjawab sampai jawaban benar. Hasil data waktu dan frekuensi menjawab digunakan untuk membuat batasan reflektif dan implusif.

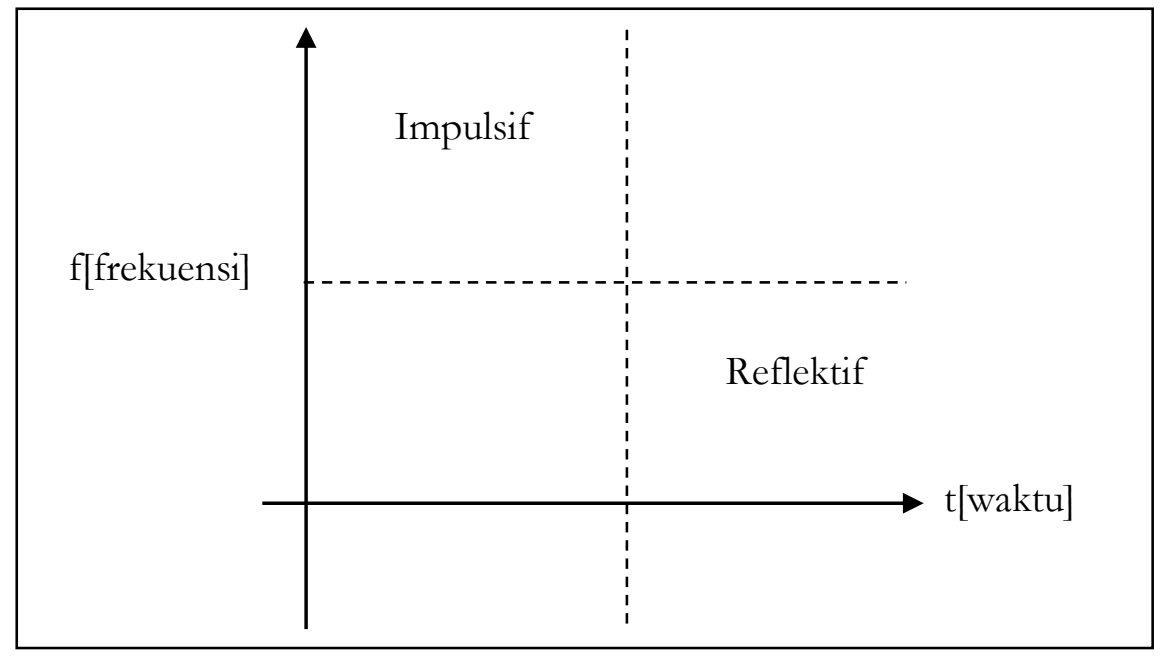

\section{Gambar 1. Tempat anak implusif-refleksif berdasarkan $t$ dan $f$}

Gambar 1 menunjukkan bahwa dalam menentukan siswa yang mempunyai gaya kognitif reflektif dan siswa yang mempunyai gaya kognitif implusif berdasarkan batasan frekuensi dan waktu. Dalam penelitian ini, tes MFF yang digunakan untuk siswa SD atau MI (usia 6 sampai dengan 12 tahun ) mengadopsi tes MFF yang dikembangkan oleh Marpaung dengan mengacu pada tes MFF yang dikembangkan Kagan. Pengembangan tes dilakukan dengan cara memberikan gambar (standar atau variasi) yang lebih komplek. 
Kompleksitas gambar dapat dilakukan dengan cara: jumlah variasi gambar diperbanyak atau gambar lebih komplek. Gambar yang diberikan berhubungan dengan matematika, misal bangun-bangun geometri, diagram yang sudah pernah dikenal di SD atau MI.

Berdasarkan uraian diatas, maka disusun hipotesis penelitian ini yaitu ada perbedaan kemampuan menyelesaikan soal cerita antara siswa yang mempunyai gaya kognitif reflektif dan siswa yang mempunyai gaya kognitif implusif kelas $\mathrm{V}$ semester 2 MI Nurul Huda Ketambul Palang Tuban Tahun Pelajaran 2013/2014. Adapun tujuan penelitian ini adalah adalah untuk mengetahui adanya perbedaan kemampuan menyelesaikan soal cerita antara siswa bergaya kognitif reflektif dan siswa bergaya kognitif implusif kelas V semester 2 MI Nurul Huda Ketambul Palang Tuban Tahun Pelajaran 2013/2014.

\section{Metode Penelitian}

Jenis penelitian yang digunakan adalah studi komparasi, dengan menggunakan pendekatan kuantitatif. Tempat penelitian di MI Nurul Huda Ketambul Palang Tuban. Teknik dalam pengambilan sampel disini adalah dengan menggunakan tes MFF. Sampel dalam penelitian ini adalah siswa kelas V MI Nurul Huda Ketambul yang mempunyai gaya kognitif reflektif dan mempunyai gaya kognitif impulsif. Teknik pengumpulan data meliputi tes MFF dan tes menyelesaikan soal cerita. Instrumen penelitian terdiri dari soal tes MFF dan soal cerita. Setelah diperoleh data hasil penelitian, selanjutnya dianalisis dengan menggunakan uji kesamaan dua rata-rata dengan statistik-t, yang sebelumnya diuji terlebih dahulu normalitas dan homogenitas.

\section{Hasil Penelitian dan Pembahasan}

Sampel dalam penelitian ini adalah siswa kelas V MI Nurul Huda Ketambul Palang Tuban yang telah diberikan tes MFF (Matching Familiar Figures). Tes MFF bertujuan untuk menentukan siswa bergaya kognitif Reflektif dan siswa yang bergaya kognitif Impulsif. Dari hasil tes tersebut selanjutnya dicari nilai median dengan caramengurutkan dari nilai terkecil hingga nilai terbesar kemudian diambil nilai tengah dengan hasil seperti disajikan pada Tabel 1 sebagai berikut:

Tabel 1. Data Gaya Kognitif Siswa Kelas V MI Nurul Huda Ketambul Palang.

\begin{tabular}{llccc}
\hline No & Nama & t(detik) & Frekuensi & Gaya Kognitif \\
1 & Imam roghib S & 13,4 & 2,8 & - \\
2 & Abdul malik & 21,5 & 3,1 & Impulsif \\
3 & Abdul jalil & 20,4 & 3,4 & Impulsif \\
4 & Qomarul afia R & 23,4 & 2,4 & Reflektif \\
5 & Wisma sanjaya & 22,1 & 2,5 & Reflektif \\
6 & Ida sujannah & 15,6 & 2,9 & Impulsif \\
7 & Siti nur hidayah & 24 & 2,6 & Reflektif \\
8 & Eka nur r & 29,4 & 3,4 & - \\
9 & Zahro & 22,9 & 3,6 & - \\
10 & Nur setiawati & 21,2 & 2,1 & - \\
11 & Indahwati & 19,5 & 3,13 & Impulsif \\
12 & Asrizi & 25,1 & 2,38 & Reflektif \\
13 & M. luqid & 26,5 & 2,75 & Reflektif \\
14 & Roif syaifudin & 16 & 3,25 & Impulsif \\
15 & Abdullah & 17, & 3 & Impulsif \\
\hline
\end{tabular}




\begin{tabular}{llccc}
\hline No & Nama & t(detik) & Frekuensi & Gaya Kognitif \\
\hline 16 & Rizqi & 19,9 & 3,13 & Impulsif \\
17 & Taufiqyr rohman & 24,7 & 2,5 & Reflektif \\
18 & Thoyib maulana $r$ & 27,9 & 3,63 & - \\
19 & Ahmad khoirul & 30,1 & 2,25 & Reflektif \\
& haqqi & & & \\
\hline
\end{tabular}

Berdasarkan data pada Tabel 1 dapat disajikan grafik scatter seperti disajikan pada Grafik 1 berikut:

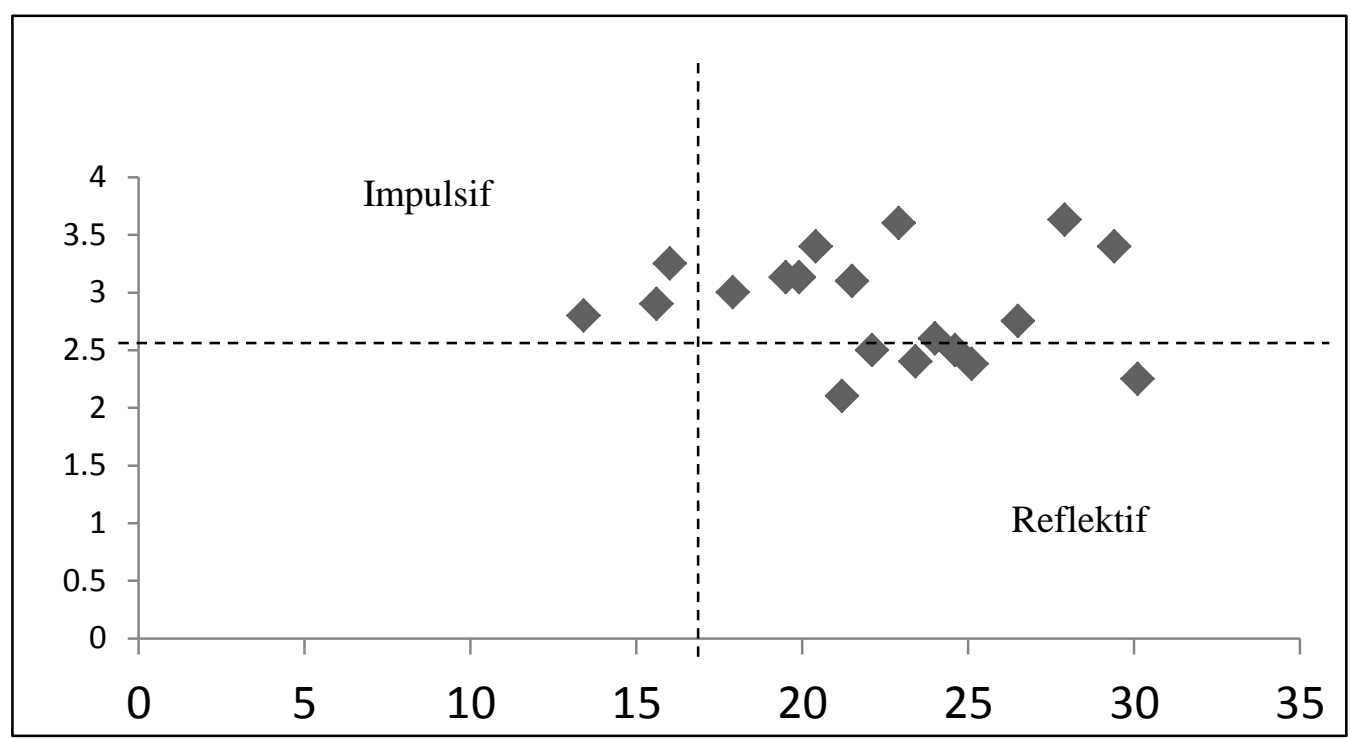

Grafik 1. Tempat Siswa Impulsif danReflektif

Berdasarkan hasil tes tersebut didapatkan data siswa yang mempunyai gaya kognitif reflektif dan siswa yang mempunyai gaya kognitif impulsif seperti disajikanpada Tabel 2 berikut.

Tabel 2. Hasil Tes MFF

\begin{tabular}{lccc}
\hline \multirow{2}{*}{ Kategori } & \multirow{2}{*}{ Jumlah } & \multicolumn{2}{c}{ Siswa } \\
\cline { 3 - 4 } & 2 siswa & Laki-laki & Perempuan \\
\hline $\begin{array}{l}\text { Cepat dan cenderung benar } \\
\begin{array}{l}\text { Cepat tapi cenderung } \\
\text { salah(Impulsif) }\end{array}\end{array}$ & 7 siswa & 5 anak & 1 anak \\
$\begin{array}{l}\text { Lambat tapi cenderung benar } \\
\text { (Reflektif) }\end{array}$ & 7 siswa & 5 anak & 2 anak \\
Lambat cenderung salah & 3 siswa & 1 anak & 2 anak \\
\hline
\end{tabular}

Dari data pada Tabel 2 tampak bahwa terdapat 7 siswa memiliki gaya kognitif impulsif, 7 siswa memiliki gaya kognitif reflektif, dan 5 siswa tidak termasuk gaya kognitif impulsif atau gaya kognitif reflektif. Prosentase banyak siswa dengan gaya kognitif berbeda-beda disajikan pada Grafik 2. Data kemampuan siswa bergaya kognitif Reflektif dan gaya kognitif Impulsif dalam menyelesaikan soal cerita matematika pokok bahasan 
volume kubus dan balok siswa kelas V MI Nurul Huda Ketambul Palang Tuban Tahun Pelajaran 2013/2014 disajikan pada Tabel 3 sebagai berikut:

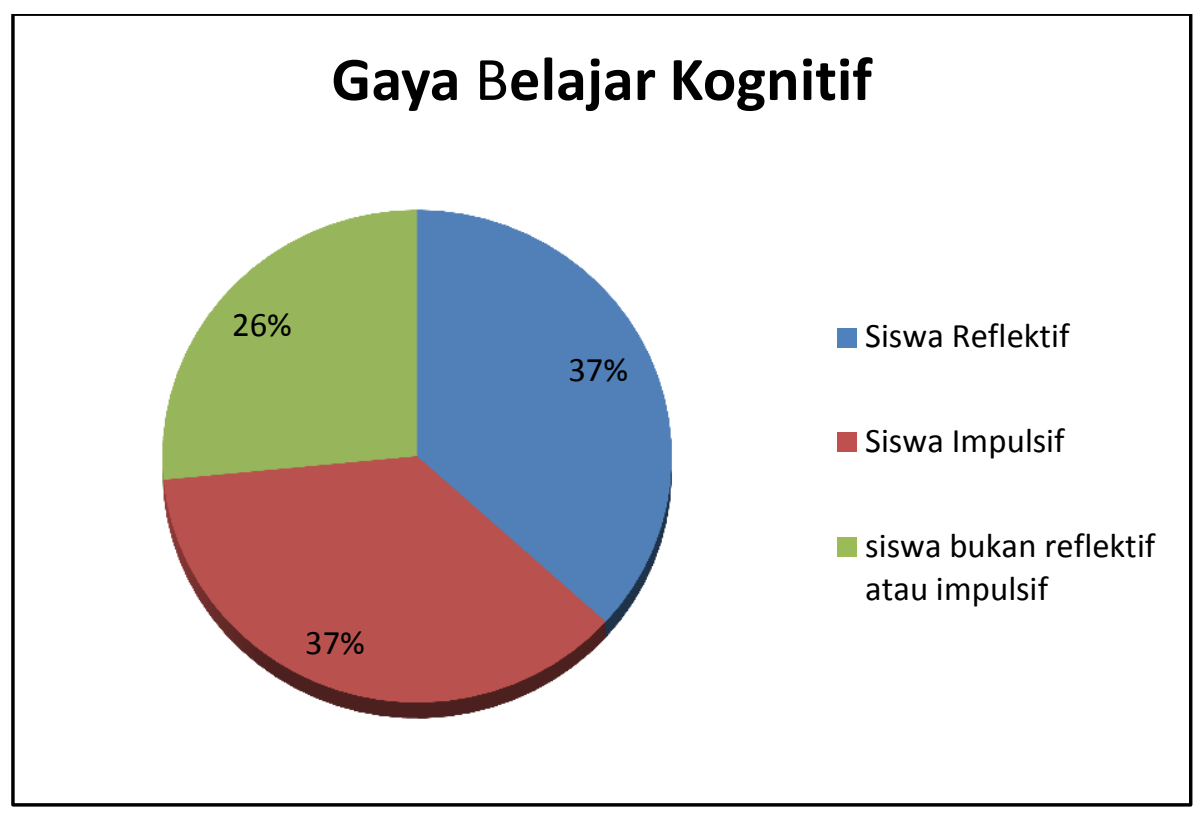

Grafik2. Diagram lingkaran siswa bergaya kognitif impulsif dan siswa bergaya kognitif reflektif

Tabel 3.Analisis Soal 14 Siswa untuk 10 Butir Soal Cerita

\begin{tabular}{clcccccc}
\hline \multirow{2}{*}{ No Nama } & \multicolumn{9}{c}{ Nomor butir soal tes matematika } & $\begin{array}{c}\text { Skor } \\
\text { Total }\end{array}$ \\
\cline { 3 - 8 } & & 1 & 2 & 3 & 4 & 5 & \\
\hline 1 & Qomarul Afia R & 18 & 18 & 17 & 13 & 12 & 80 \\
2 & Wisma Sanjaya & 18 & 16 & 13 & 14 & 15 & 76 \\
3 & Siti Nurhidayah & 18 & 14 & 17 & 15 & 19 & 72 \\
4 & Abdul Malik & 16 & 14 & 14 & 13 & 13 & 70 \\
5 & Indahwati & 18 & 16 & 14 & 15 & 12 & 75 \\
6 & Asrizi & 18 & 18 & 19 & 18 & 17 & 90 \\
7 & M. Luqid & 18 & 18 & 14 & 15 & 16 & 81 \\
8 & Roif Syaifudin & 18 & 18 & 16 & 18 & 16 & 86 \\
9 & Abdullah & 16 & 15 & 10 & 10 & 14 & 65 \\
10 & Rizqi & 16 & 12 & 11 & 10 & 14 & 63 \\
11 & Taufiqurrohman & 18 & 16 & 14 & 16 & 18 & 82 \\
12 & Ahmad Qoirul Haqqi & 18 & 16 & 13 & 13 & 12 & 75 \\
13 & Abdul Jalil & 18 & 17 & 14 & 19 & 15 & 72 \\
14 & Ida Sujjanah & 18 & 16 & 14 & 15 & 12 & 68 \\
\hline
\end{tabular}

Dari hasil tes kemampuan menyelesaikan soal cerita pokok bahasan volume kubus dan balok selanjutnya dilakukan uji normalitas dan homogenitas. Karena data dalam penelitian ini kurang dari 30 (14 siswa), maka uji normalitas dalam penelitian ini diabaikan. Untuk selanjutnya analisis statistik yang digunakan untuk hipotesis penelitian ini adalah uji nonparametik Mann-Whitney. Uji Mann-Whitney digunakan untuk menguji dua kelompok independen atau saling bebas yang diambil dari suatu populasi. Uji ini 
merupakan alternatif lain dari Uji-t, jika skala pengukuran lebih rendah dari skala interval dan asumsi distribusi normalitas sampel dan homogenitas tidak terpenuhi. Tes Nonparametik Mann-Whitney digunakan dalam penelitian ini karena: (1)Sifat-sifat populasi tidak diketahui normal tidaknya. (2)Variabel-variabel berbentuk skala normal. (3)Asumsiasumsi parametik tidak dapat dipenuhi.

Dari hasil perhitungan Mann-Whitney dengan menggunakan SPSS 16 diperoleh harga $U_{\text {hitung }}$ adalah merupakan jumlah rangking terkecil. Dengan melihat tabel kuantilkuantil statistik Uji Mann-Whitney untuk $\mathrm{n}_{1}=7, \mathrm{n}_{2}=7$ dan $\mathrm{p}=0,025$ didapat $U_{\text {tabel }}=9$. Berarti $U_{\text {hitung }}=8<U_{\text {tabel }}=9$, dan harga Asymp.sig 0,035. Karena Sig $<0,05$ maka Ho ditolak. Dengan demikian dapat disimpulkan bahwa ada perbedaan kemampuan menyelesaikan soal cerita antara siswa yang bergaya kognitif Reflektif dan siswa yang bergaya kognitif Impulsif Kelas V MI Nurul Huda Ketambul Palang Tuban Tahun Pelajaran 2013/2014. Perbedaan ini dapat dilihat dari nilai rata-rata antara siswa yang mempunyai gaya kognitif Reflektif yaitu 80,2 dan siswa yang mempunyai gaya kognitif Impulsif yaitu 70,4.

Siswa bergaya kognitif Impulsif membutuhkan waktu yang relatif lebih singkat dari pada siswa bergaya kognitif Reflektif dalam menyelesaikan soal cerita. Karakteristik lainnya dari siswa Impulsif adalah penyelesaian yang dihasilkan cenderung salah, kurang teliti. Siswa Impulsif cenderung tidak melalui tahap merencanakan penyelesaian, buram perhitungan yang cenderung hanya sedikit, serta enggan memeriksa kembali penyelesaian yang telah ditemukan. Berbeda halnya dengan siswa Reflektif. Mereka membutuhkan waktu yang lebih lama dalam menyelesaikan soal yang diberikan. Membaca berulangulang untuk memahami masalah, merencanakan penyelesaian dengan cara merancang, menggambar, menuliskan rumus serta melakukan perhitungan pada kertas buram yang diberikan. Setelah itu, baru menuliskan penyelesaian pada lembar jawaban. Siswa Reflektif akan memeriksa kembali bahkan berulang kali penyelesaian yang telah ditemukan.

Kagan dan Kogan (1970) mengatakan bahwa anak impulsif menjawab dengan cepat dan membuat banyak kesalahan dibanding anak reflektif dalam kualitas penalaran induktif. Sedangkan Kinney (dalam Warli, 2010) menunjukkan anak reflektif usia 7 tahun lebih komunikatif dengan tanggapan mereka dibanding anak impulsif. Faktor metodologis yang mempengaruhi dalam penelitian ini adalah para siswa reflektif cenderung menjawab secara acak-acakan karena sesuai dengan karakteristik mereka yaitu cenderung membutuhkan waktu berfikir yang lama untuk memutuskan jawaban yang benar. Sementara siswa impulsif dapat menghasilkan jawaban yang lebih cepat tanpa ada pertimbangan lain.Faktor non metodologis yang mempengaruhi yaitu adanya variabelvariabel yang tidak terkontrol dalam penelian ini, seperti kondisi sosial siswa, kondisi psikologis siswa pada saat tes dan lain-lain.

Hasil penelitian ini sejalan dengan penelitian yang telah dilakukan oleh (Warli, 2010) bahwa salah satu responden yang bergaya kognitif impulsif dalam waktu 20 menit mampu membuat delapan gambar segi empat. Namun dari delapan gambar yang dihasilkan, hanya ada dua buah gambar yang benar. Responden ini mempunyai ide rencana dan langsung mengerjakan pada lembar jawaban. Hanya sebentar saja ia mencoba-coba pada kertas coretan. Hal ini bisa dibuktikan bahwa coretan relatif sedikit. Ia juga tidak mengoreksi hasil jawaban yang telah ditulis pada lembar jawaban, sehingga jawaban cenderung salah. Sedangkan responden lain adalah siswa bergaya kognitif refektif. Dalam waktu yang sama (20 menit) ia hanya mampu membuat empat buah gambar segi empat dan semuanya bernilai benar. Apabila dicermati walaupun sedikit gambar yang dibuat oleh responden tetapi cenderung unik (tidak biasa), dan berdasarkan hasil klarifikasi ia mencoba dulu berkali-kali pada lembar coretan, serta diakhir pekerjaannya ia mengoreksi hasil pekerjaannya sehingga jawaban cenderung benar. 
Rahmatina (2014) mengatakan bahwa pada masalah bangun datar subjek reflektif mampu membuat bentuk bangun datar yang baru dan unik, sedangkan subjek impulsif sebagian ada yang dapat dan sebagian lainnya tidak dapat membuat bangun datar. Selain itu, subjek reflektif juga fleksibel dalam membuat bangun datar tersebut yaitu dengan dua cara yang berbeda, sedangkan subjek impulsif tidak. Pada masalah persamaan garis subjek reflektif mampu membuat persamaan garis dengan cara yang baru, sedangkan subjek impulsif tidak.

Dalam penelitian yang dilakukan masih terdapat kelemahan dalam meneliti. Kelemahan tersebut antara lain:

a. Peneliti tidak melakukan pengajaran tetapi hanya memberikan tes kepada subjek untuk mengetahui kemampuan menyelesaikan soal cerita.

b. Hasil penelitian tidak mutlak karena perbedaan gaya kognitif siswa masing-masing, tetapi bisa jadi perbedaan itu bersumber dari pengajaran yang sudah dilakukan oleh guru.

\section{Simpulan}

Berdasarkan hasil penelitian dapat disimpulkan bahwa ada perbedaan kemampuan antara siswa yang bergaya kognitif Reflektif dan siswa yang bergaya kognitif Impulsif dalam menyelesaikan soal cerita pada pokok bahasan volume balok dan kubus kelas V MI Nurul Huda Ketambul Palang Tuban tahun pelajaran 2013/2014. Siswa bergaya kognitif Reflektif mempunyai nilai rata-rata 80,2 sedangkan siswa yang bergaya kognitif Impulsif nilai rata-rata 70,4. Perbedaan nilai rata-rata ini disebabkan karakteristik dari siswa impulsif dalam menyelesaikan soal cerita dalam waktu yang relatif singkat dan cenderung salah dalam penyelesaiannya. Siswa Impulsif cenderung tidak melalui tahap merencanakan penyelesaian, buram perhitungan yang cenderung hanya sedikit, serta enggan memeriksa kembali penyelesaian yang telah ditemukan.

\section{Daftar Pustaka}

Hudojo, H. (2001). Pengembangan Kurikulum dan Pembelajaran Matematika. Malang: Universitas Negeri Malang.

Kagan, J. (Ed). (1965). Impulsif dan Reflektif children: significance of conceptual tempo. Chicago: Rand McNally and Company.

Kagan, J.,\& Kogan, N. (1970).Individual Variation in Cognitive Process. Dalam Mussan, P. (Edt.) Carmichael's Manual of Child Psychology (3rd ed. Vol. 1) Wiley New York.

Kenny, Robert F. (2007).Digital Narrative as a Change Agent to Teach Reading to Media-Centric Student. International Journal of Social Sciences, 2(3).

Rahmatina, S. (2014). Tingkat Berpikir Kreatif Siswa dalam Menyelesaikan Masalah Matematika Berdasarkan Gaya Kognitif Reflektif dan Impulsif. Jurnal Didaktik Matematika, 1(1).

Rozencwajg, Paulette \& Corroyer, Denis. (2005) Cognitive Processes in the Reflective-Impulsive Cognitive Style. The Journal of Genetic Psychology, 2005, 166(4), 451 - 463.

Soedjadi, R. (2000). Kiat Pendidikan Matematika di Indonesia, Jakarta: Direktorat JendralPendidikan Tinggi, Departemen Pendidikan Nasional.

Solso, Robert L. (1995) Cognitive Psychology. Third Edition, Boston: Allyn \& Bacon

Warli. (2010). "Profil Kreativitas Siswa yang Bergaya Kognitif Reflektif dan Siswa yang Bergaya Kognitif Impulsif dalam Memecabkan Masalah Matematika". Disertasi. PPs UNESA Surabaya. 
Witkin, H.A., Moore, C.A., Gooddenough, D.R.,\& Cox, P.W. (1977) Field Dependent and Field Independent Cognitive Style and Their Educational Implication. Review of Educational Research.

Lampiran 1. Instrumen soal cerita pokok bahasan kubus dan balok

\section{Petunjuk :}

Selesaikanlah permasalahan berikut dengan tepat pada lembar jawaban yang telah disediakan!

Dalam menyelesaikan permasalahan, gunakanlah langkah-langkah pemecahan masalah, yang meliputi empat langkah, yaitu:

$>\quad$ Memahami masalah, dengan cara menuliskan apa yang diketahui dan apa yang ditanyakan.

Merencanakan strategi penyelesaian

Menerapkan strategi penyelesaian dan perhitungan dengan benar

Memeriksa kembali jawaban yang sudah dihasilkan

1. Made akan membuat 15 buah kerangka balok yang masing-masing berukuran 30 $\mathrm{cm} \times 20 \mathrm{~cm} \times 15 \mathrm{~cm}$. Bahan yang akan digunakan terbuat dari kawat yang harganya Rp 1.500/m. Hitunglah jumlah panjang kawat yang diperlukan untuk membuat balok tersebut dan hitunglah biaya yang diperlukan untuk membeli bahan/kawat!

2. Diketahui sebatang kawat mempunyai panjang $236 \mathrm{~cm}$. Kawat itu akan dibuat dua model kerangka yaitu yang berbentuk kubus dan balok. Jika ukuran balok tersebut $(12 \times 8 \times 5) \mathrm{cm}$, tentukan panjang rusuk kubus!

3. Sukma memiliki kawat sepanjang $156 \mathrm{~cm}$. Ia ingin menggunakan kawat tersebut untuk membuat kerangka kubus. Berapa panjang rusuk kubus agar kawat tidak bersisa!

4. Kawat dengan panjang $9 \mathrm{~m}$ akan dibuat 5 buah model kerangka kubus. Berapa panjang maksimal rusuk yang harus dibuat agar menghasilkan 5 buah model kerangka kubus? 
Lampiran 2. Contoh soal tes MFF

Petunjuk: Gambar tersebut ada 2 bagian, pertama gambar standar (baku) sebanyak 1 gambar. Dan kedua adalah gambar variasi (stimulus) sebanyak 8 gambar. Diantara gambar variasi ada 1 gambar yang sama dengan gambar standar. Sebutkan gambar nomor berapa dari gambar variasi yang sama dengan gambar standar!

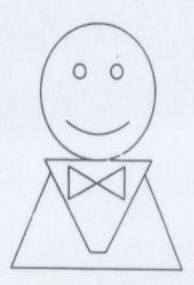

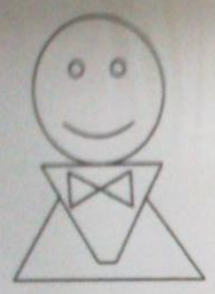

1

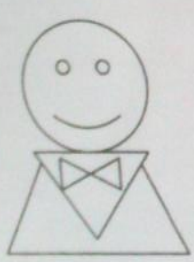

5

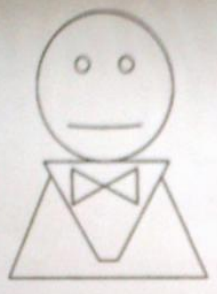

2

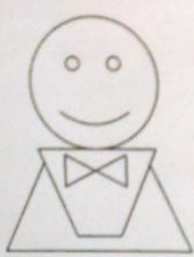

6

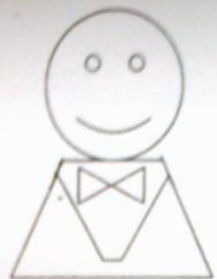

3

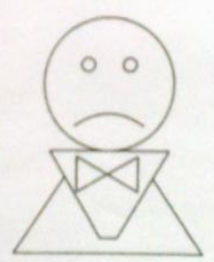

7
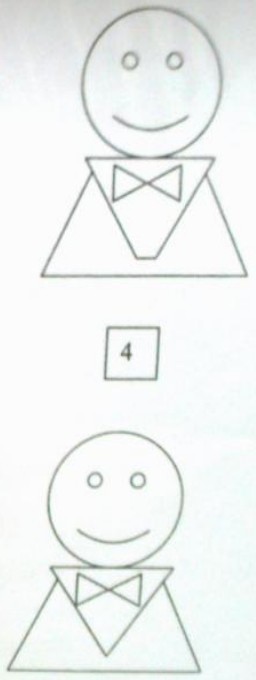

8 

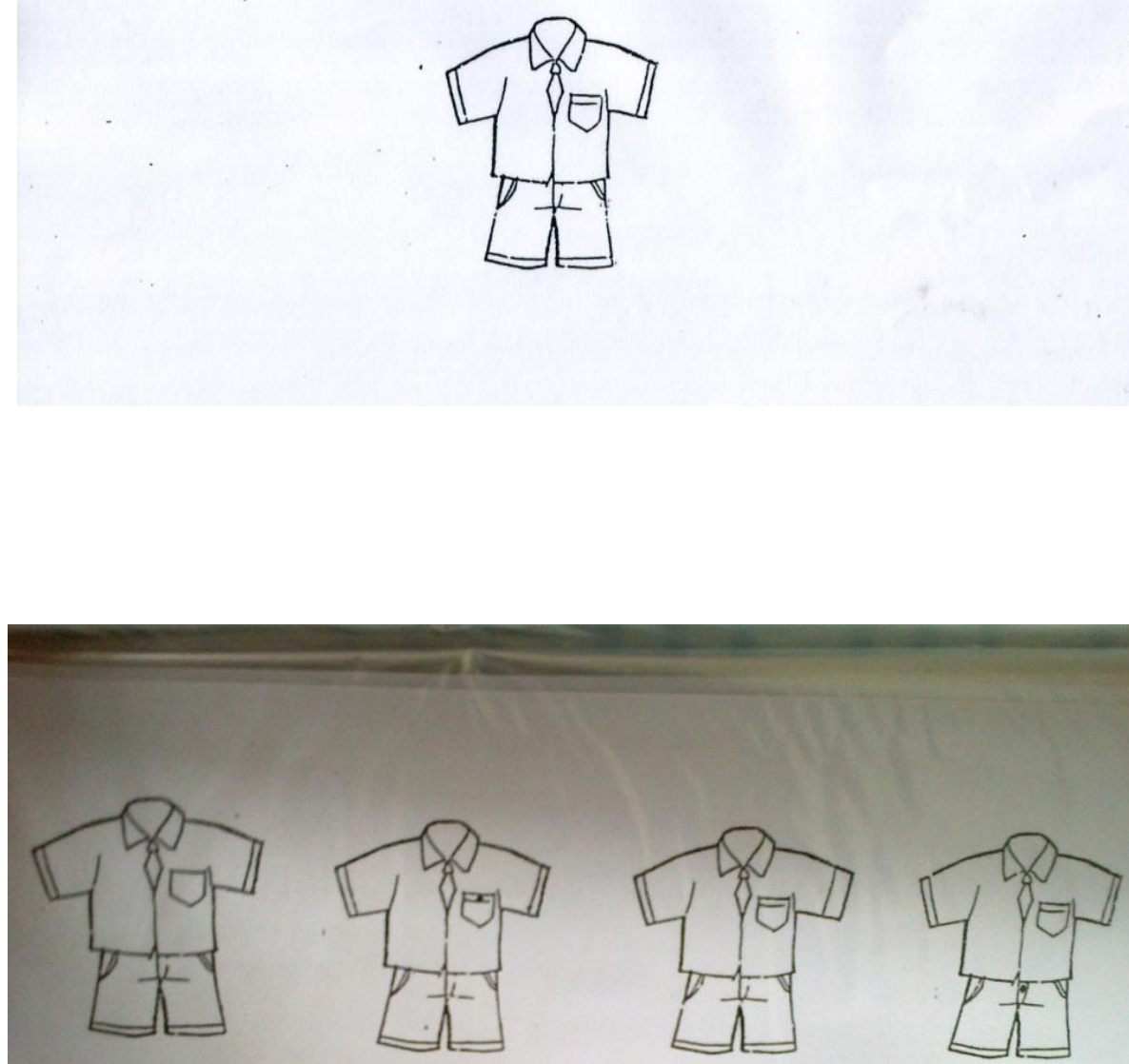

1

2

3

4
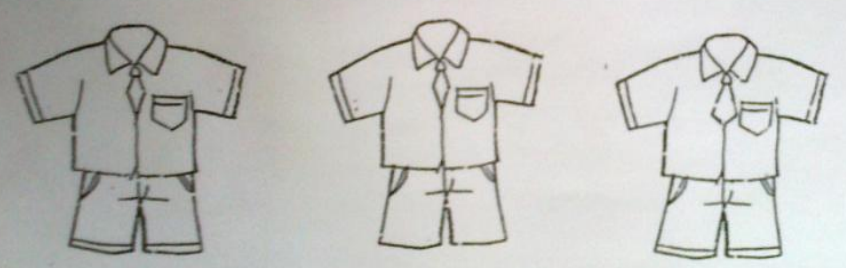

7

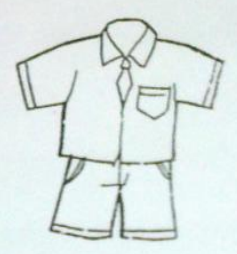

6

8 